\title{
Implementasi Konsep Bioentrepreneurship Berbasis Potensi Lokal Melalui Pelatihan Pembuatan Nata de Cashew
}

\author{
Agus Muliadi ${ }^{*}$, Baiq Mirawati ${ }^{2}$, Iwan Doddy Dharmawibawa ${ }^{3}$, Suryati $^{4}$ \\ 1,2,3Prodi Pendidikan Biologi, FSTT, Universitas Pendidikan Mandalika, J1. \\ Pemuda No. 59 A, Mataram, Indonesia 83125 \\ ${ }^{4}$ Pendidikan Kimia, FSTT, Universitas Pendidikan Mandalika \\ e-mail Korespondensi: agusmuliadi@ikipmataram.ac.id
}

Diterima: Maret 2021; Revisi: April 2021; Diterbitkan: Juni 2021

\begin{abstract}
The aim of this activity is to increase the knowledge and skills of farmers in processing cashew nuts into Nata de Cashew. The participants of this activity were the people of the village of Menggala as many as 17 people. The training activities are carried out in three stages, namely (1) preparation, (2) implementation, (3) evaluation. The result of the training was that the implementation of the bioentrepreneurship concept through training and mentoring in making Nata de Cashew was effective in increasing the knowledge and skills of the participants. This is evidenced by the results of observations, namely: (1) the mastery of the material and skills of the participants in making Nata de Mete is categorized as Good; (2) the quality of the Nata de Mete produced is categorized as Good; (3) Participants' motivation, interest, and cooperation during the training and mentoring implementation were categorized as Very Good; (4) Participants' motivation for independent cashew nut production is also categorized as Good.
\end{abstract}

Keywords: Bioentrepreneurship, Local Potential, Nata De Cashew

\begin{abstract}
Abstrak
Tujuan kegiatan ini adalah untuk meningkatkan pengetahuan dan keterampilan petani dalam mengolah buah jambu mete menjadi Nata de Cashew. Peserta kegiatan ini adalah masyarakat Dusun Menggala sebanyak 17 orang. Kegiatan pelatihan dilakukan dalam tiga tahap yaitu (1) Persiapan, (2) Pelaksanaan, (3) Evaluasi. Hasil kegiatan pelatihan bahwa implementasi konsep bioentrepreneurship melalui pelatihan dan pendampingan pembuatan Nata de Cashew efektif untuk meningkatkan pengetahuan dan keterampilan peserta. Hal ini dibuktikan dengan hasil observasi yaitu: (1) penguasan materi dan keterampilan peserta dalam membuat Nata de Cashew dikategorikan Baik; (2) kualitas Nata de Cashew yang dihasilkan dikategorikan Baik; (3) Motivasi, minat, dan kerjasama peserta selama pelaksanaan pelatihan dan pendampingan dikategorikan Sangat Baik; (4) Motivasi peserta untuk produksi Nata de Cashew secara mandiri juga dikategorikan Baik.
\end{abstract}

Kata kunci: Bioentrepreneurship, Potensi Lokal, Nata De Cashew

How to Cite: Muliadi A., Mirawati B., Dharmawibawa D.I., Suryati. (2021). Implementasi Konsep Bioentrepreneurship Berbasis Potensi Lokal Melalui Pelatihan Pembuatan Nata de Cashew. SASAMBO: Jurnal Abdimas (Journal of Community Service). 3(2), 49-56. doi: $10.36312 /$ sasambo.v3i2.421 


\section{LATAR BELAKANG}

Jambu mete (Anacardium occidentale L.) merupakan salah satu komoditas perkebunan yang cukup menjanjikan di Lombok Utara. Produksi buah jambu mete cukup tinggi tiap tahunnya (Muliadi \& Arjun, 2018). Pada tahun 2013, produksi jambu mete di Lombok Utara yaitu sebanyak $2.727,21$ ton dengan rata-rata produksi mencapai $364,49 \mathrm{~kg} / \mathrm{ha}$. Masyarakat memanfaatkan hanya biji jambu mete untuk dijual, sedangkan daging buahnya belum dimanfaatkan secara maksimal. Daging buah jambu mete dimanfaatkan secara terbatas oleh masyarakat, hanya sebagai pakan ternak dan/atau dikonsumsi sendiri. Hal ini diakibatkan karena rasa daging buah jambu mete yang kecut, karena adanya kandungan tanin yang tinggi dalam daging buah jambu mete. Akibatnya, daging buah jambu mete sebagian besar terbuang secara percuma di area perkembunan atau ditimbun pada lubang khusus yang dibuat petani di area perkebunan. Oleh sebab itu, diperlukan adanya inovasi teknologi untuk mengolah produksi daging buah jambu mete menjadi produk komersil lainnya.

Pemanfaatan daging buah jambu mete dapat dilakukan berbasis ilmu bioteknologi (Muliadi, 2020). Bioteknologi merupakan cabang ilmu biologi yang memiliki materi bersifat aplikatif/terapan tentang kajian mahluk hidup dan lingkungannya (sumber daya alam), sehingga hendaknya dibelajarkan secara kontekstual berdasarkan potensi dan kearifan lokal (Muliadi, 2019; Muliadi, 2020). Oleh sebab itu, keilmuan bioteknologi yang bersifat terapan sangat memungkinkan untuk melakukan inovasi dalam memanfaatkan produksi potensi lokal seperti daging buah jambu mete berbasis nilai-nilai kewirausahaan (Muliadi, 2020; Muliadi, Mirawati \& Azmi, 2020).

Konsep keilmuan bioteknologi memiliki ruang lingkup yang berkaitan dengan produktivitas dengan muatan nilai wirausaha (entrepreneur) seperti pemanfaatan mikroorganisme untuk mempercepat proses produktivitas (Anwar, Supardi \& Sugiharto, 2012). Muliadi, Mirawati \&Azmi (2020) menyatakan bahwa nilai-nilai kewirausahaan memiliki relevansi untuk diitegrasikan dalam konsep bioteknologi yang bersifat aplikatif. Hal ini ditegaskan oleh pendapat Natadiwijaya, et al. (2018) bahwa kewirausahaan dapat dikembangkan salah satunya melalui penciptaan produk-produk berbasis biologi terapan/aplikatif.

Konsep bioteknologi yang diintegrasikan dengan muatan nilai-nilai kewirausahaan dikenal dengan istilah bioentrepreneurship (Anwar, Supardi \& Sugiharto, 2012; Natadiwijaya, et al., 2018; Muliadi, 2020). Konsep bioentrepreneurship dapat diaplikaskan untuk memanfaatkan potensi lokal seperti pengolahan daging buah jambu mete menjadi Nata de Cashew. Produksi Nata de Cashew memanfaatkan mikroorganisme yaitu bakteri Acetobacter xylinum sebagai starter (bioaktivator) untuk mempercepat proses fermentasi. Oleh sebab itu, bioentrepreneurship dapat diimplementasikan untuk memfasilitasi penguatan pengetahuan dan keterampilan (skill) yang dibutuhkan bagi seorang wirausaha yang tertarik kepada komersialisasi produk-produk hasil pemanfaatan ilmu hayati (Langer, 2014), seperti jambu mete yang menjadi potensi lokal daerah Lombok Utara (Muliadi \&Arjun, 2018). Hal ini sesuai dengan kebijakan 
pemerintah saat ini yaitu Jaring Pengaman Sosial (JPS) dengan salah satu programnya yaitu Tenaga Kerja Mandiri (TKM) untuk penciptaan wirausaha yang dapat membuka lapangan kerja maupun usaha bagi masyarakat. Program tersebut dapat menjadi stimulus bagi masyarakat pelaku industri kecil guna meningkatkan kreativitas dalam pemanfaatan potensi sumber daya alam (Avisena, 2020).

Impelementasi konsep bioentrepreneurship dalam memanfaatkan daging buah jambu mete di Lombok Utara dapat dilakukan melalui berbagai bentuk kegiatan pemberdayaan seperti pelatihan, workshop, dan pendampingan untuk menguatkan pengetahuan dan keterampilan (skill) masyarakat. Pelatihan masyarakat berbasis bioentrepreneurship sangat bermanfaat untuk menguatkan pengetahuan dan keterampilan dalam memanfaatkan potensi jambu mete yang luar biasa secara efektif dan bijaksana (Muliadi, Mirawati \& Azmi, 2020). Kegiatan pelatihan berbasis bioentrepreneurship bagi masyarakat dalam mengolah potensi lokal berupa jambu mete menjadi produk komersil yang memiliki nilai ekonomis dapat meningkatkan pendapatan dan kesejateraan hidup masyarakat (Muliadi \& Arjun, 2018). Pelatihan masyarakat berbasis bioentrepreneurship pada akhirnya dapat meningkatkan kecakapan hidup (life skill) dan peluang usaha bagi masyarakat (Afriadi \& Yuni, 2018), melalui pemanfaatan buah jambu mete yang menjadi potensi lokal yang melimpah di Lombok Utara.

Masyarakat Desa Menggala Kabupaten Lombok Utara memiliki produksi jambu mete yang melimpah (Muliadi \& Arjun, 2018). Masyarakat hanya memanfaatkan biji jambu mete, mengakibatkan melimpahnya daging buah jambu mete yang dapat dimanfaatkan menjadi Nata de Cashew. Hal ini sesuai pendapat Harsojuwono, Arnata \& Yulianti (2017) bahwa buah semu/daging buah mete memiliki potensi yang sangat besar untuk diolah menjadi berbagai produk komersil yaitu Nata de Cashew. Produksi Nata de Cashew dapat dioptimalkan menjadi wirausaha baru bagi masyarakat petani jambu mete untuk meningkatkan kesejahteraan. Kendati demikian, masyarakat selama ini masih terkendala oleh rendahnya pengetahuan dan keterampilan dalam mengolah daging buah jambu mete menjadi produk komersil lainnya. Oleh sebab itu, kegiatan pelatihan pengolahan daging buah jambu mete menjadi Nata de Cashew menjadi solusi tepat untuk membangun kreativitas, keterampilan, dan kemandirian masyarakat petani.

\section{METODE PELAKSANAAN}

Kegiatan pemberdayaan masyarakat ini dilaksanakan menggunakan pendekatan partisipatif, yaitu berorientasi kepada upaya meningkatkan peran serta masyarakat dalam berbagai proses dan pelaksanaannya (Muliadi, Mirawati \& Azmi, 2020). Kegiatan ini diselanggarakan dalam bentuk pelatihan dan pendampingan yang diikuti oleh masyarakat petani jambu mete di Dusun Menggala sebanyak 17 orang. Adapun tahapan pelaksanaan kegiatan ini adalah sebagai berikut:

\section{Peserta Kegiatan}

Peserta kegiatan pemberdayaan masyarakat ini adalah masyarakat petani jambu mete di Dusun Menggala Lombok Utara. 
2. Tahap Persiapan

Pada tahap ini dilakukan observasi lapangan dan koordinasi dengan masyarakat petani jambu mete di Dusun menggala yang diwakili oleh Kepala Dusun (KADUS). Tujuan kegiatan ini adalah (1) untuk mendiskusikan tentang tingkat produksi jambu mete, pemanfaatan buah semi/daging buah oleh petani selama ini, waktu dan mekanisme pelaksanaan; (2) pelaksanaan pemberdayaan disepakati dilaksanakan melalui kegiatan pelatihan dan pendampingan; (3) persiapan lokasi, alat dan bahan untuk pelatihan dan pendampingan pembuatan Nata de Cashew.

3. Tahap Pelaksanaan

Kegiatan pelatihan dan pendampingan akan dilakukan 4 pertemuan dengan rincian yaitu pelatihan 1 pertemuan dan pendampingan 3 pertemuan. Kegiatan pelatihan dilakukan menggunakan metode ceramah, diskusi, dan demonstrasi dengan tujuan untuk menguatkan pengetahuan peserta tentang bahan, alat, dan tahapan pembuatan Nata de Cashew. Sedangkan kegiatan pendampingan dilakukan dengan mendampingi peserta dalam membuat Nata de Cashew, dengan tujuan untuk menguatkan keterampilan peserta dalam membuat Nata de Cashew.

4. Tahap Evaluasi

Pada tahap ini dilakukan evaluasi di akhir kegiatan dengan metode observasi menggunakan lembar observasi dengan indikator yaitu motivasi dan minat, kerjasama dan kolaborasi, pengetahuan, keterampilan, kualitas Nata de Cashew yang dihasilkan, dan keberlanjutan pembuatan Nata de Cashew secara mandiri. Penilaian diberikan kategori Sangat Baik, Baik, Kurang Baik, dan Tidak Baik (Muliadi, 2020).

\section{HASIL DAN PEMBAHASAN}

Kegiatan pemberdayaan masyarakat melalui metode pelatihan dan pendampingan ini bertujuan untuk meningkatkan pengetahuan dan keterampilan masyarakat petani jambu mete di Dusun Menggala dalam mengolah daging buah/buah semu jambu mete menjadi Nata de Cashew. Elaborasi hasil kegiatan pelatihan dan opendampingan ini dilakukan sesuai tahapannya yaitu:

\section{Tahap Perencanaan}

Pada tahap perencanaan ini, tim melaksanakan beberapa kegiatan persiapan awal dengan hasil yaitu: (a) hasil observasi lapangan menunjukkan bahwa petani umumnya menimbun daging buah/buah semu jambu mete di area perkebunan. Hal ini dikarenakan daging buah jambu mete selama ini, diakui petani belum dimanfaatkan kecuali sekedar dikonsumsi pribadi dalam jumlah yang sangat terbatas. Potensi daging buah jambu mete sangat potensial, namun karena keterbatasan pengetahuan keterampilan menjadi alasan petani belum memanfaatkan atau memproduksinya menjadi produki komersil lainnya; (b) hasil koordinasi dengan Kepala Dusun Menggala bahwa peserta pelaksanaan pelatihan diikuti oleh 17 orang ibu-ibu petani jambu mete; (c) waktu 
pelaksanaan kegiatan pelatihan dan pendampingan dilakukan sore hari agar tidak mengganggu aktivitas bertani masyarakat pada pagi hari; (d) lokasi kegiatan pelatihan dan pendampingan dilakukan di ruang pertemuan miliki Dusun Menggala; (e) tim dan masyarakat berkolaborasi menyiapkan alat dan bahan yang dibutuhkan dalam kegiatan pelatihan dan pendampingan; (e) tim menyusun materi pelatihan dan video tutorial pembuatan Nata de Casheuruntuk memudahkan peserta memahami mater pelatihan dan belajar materi secara mandiri; (e) tim menyusun lembar observasi sebagai instrumen evaluasi kegiatan.

\section{Tahap Pelaksanaan}

Pada tahap ini, tim menyelenggarakan kegiatan pelatihan dan pendampingan masyarakat dalam mengolah daging buah/buah semu jambu mete menjadi Nata de Cashew. Pelatihan dilaksanakan 1 pertemuan dan pendampingan 3 kali pertemuan. Kegiatan pelatihan dilakukan untuk memberikan penguatan konsep dengan menjelaskan dan mendemonstrasikan tentang nama dan fungsi alat dan bahan, serta prosedur pengolahan daging buah jambu mete menjadi Nata de Cashew. Metode demonstrasi digunakan untuk memudahkan peserta dalam memahami konsep, mengetahui alat dan bahan, serta dapat mempraktikkan langsung tahapan dalam membuat Nata de Cashew yang benar dan higienis. Hal ini sesuai dengan pendapat Sujarwo (2011) bahwa tutor/narasumber berperan sebagai mediator karena apa yang dipelajari oleh peserta merupakan hal penting dalam pendidikan orang dewasa, bukan apa yang diajarkan olehtutor. Pada tahap ini tutor menjelaskan dan memperkenalkan bahan-bahan pembuatan Nata de Coco seperti daging buah jambu mete, gula pasir, asam cuka, starter bakteri Acetobacter xylinum.

Penguatan konsep dapat kegiatan pelatihan dapat mengedukasi masyarakat tentang profil Nata de Cashew, nama dan fungsi dari alat dan bahan membuat Nata de Cashew dan prosedur pembuatannya. Produk yang dihasilkan adalah Nata sedangkan kata Cashew itu ditambahkan karena jambu mete yang menjadi bahan baku utama pembuatan Nata de Cashew. Nata merupakan istilah yang berasal dari bahasa Spanyol yang berartu terapung (Utami, Harianie, Kusmiyati \& Fitriasari, 2020).

Pada proses pembuatan Nata de Cashew diperoleh lapisan berwarna putih berupa selulosa mikrobial hasil perombakan gula olehbakteri Acetobacter xylinum dan akan terapung pada permukaan medium (larutan bahan), semakin lamaproses inkubasi akan semakin tebal selulosa mikrobial yang dihasilkan. Lapisan selulosa mikrobial disebut sebagai Nata (Muliadi, Mirawati \& Azmi, 2020). Pembuatan Nata umumnya membutuhkan waktu antara 10-14 hari dan harus higienis. Peralatan yang digunakan dalam pembuatan Nata de Cashewharus disterilisasi terlebih dahulu, dimana peserta diedukasi cara mensterilisasi alat menggunakan air panas agar tidak terkontaminasi terutama oleh jamur selama proses pemeraman (inkubasi) Nata. Disamping itu, peserta juga diedukasi tentang penggunaan bahan berupa gula pasir yang menjadi sumber karbon dan energi bagi bakteri Acetobacter xylinum dalam pembuatan Nata de Cashew(Warsino, 2004), sedangkan air perasan buah jambu 
metedigunakan sebagai medium pertumbuhan bakteri Acetobacter xylinum (Utami, Harianie, Kusmiyati \& Fitriasari, 2020).Cuka (asam asetat glasial) digunakan agar menjaga kondisi keasaman medium pada kisaran $\mathrm{pH} 3,5-4$ sesuai kondisi optimum untuk pertumbuhan bakteri Acetobacter xylinum (Wijayanti, Kumalaningsih \& Effendi, 2012).

Kegiatan pelatihan untuk menguatkan pengetahuan peserta yang telah diberikan, dilanjutkan dengan kegiatan pendampingan untuk membimbing pesertapraktik langsung membuat Nata de Cashew menggunakan bahan dasar daging buah/buah semu jambu mete. Prosedur pembuatan Nata de Cashew yang dipraktikkan peserta sebagai berikut: (1) sterilisasi semua alat yang akan digunakan; (2) bersihkan buah jambu mete, diblender, dan disaring kemudian dimasak; (3)dibuat larutan hasil campuran air ekstrak daging buah jambu mete dan gula pasir dengan komposisi 10\% gula/liter, selanjutnya dimasak hingga mendidih; (4) tambahkan nutrisi dan cuka (sampai $\mathrm{pH}$ 4) setelah larutan medium dingin, selanjutnya tambahkan larutan starter (Acetobacter xylinum) sebanyak $170 \mathrm{ml} /$ liter larutan medium dan aduk sampai merata; (5) masukkan campuran larutan medium tersebut ke dalam wadah fermentasi (baskom ukuran 34 × 25 x $5 \mathrm{~cm}$ ), selanjutnya wadah ditutup dengan kain saring/kertas dan diletakkan ditempat yang bersih, tidak bergerak, dan tertutup agar tidak terkontaminasi. Proses inkuasi (pemeraman) dilakukan selama 8-14 hari hingga lapisan Natamencapai ketebalan minimal $\pm 1,5 \mathrm{~cm}$ (Muliadi \& Arjun, 2016).

Nata yang dihasilkan dan kategori baik jika berwarna putih dan tekstur kenyal. Nata dipanen dengan cara diangkat, dibilar air mengalis, dan direndam dalam air selama 3 hari (airdiganti setiap hari) untuk menghilangkan aroma asam cuka. Untuk mengolah Nata, maka harus direbus dengan air gula sampai rasa asam hilang dan Nata siap dikonsumsi atau dicampur dengan bahan minuman/makanan lainnya menjadi produk komersil yang memiliki nilai ekonomi tinggi (Utami, Harianie, Kusmiyati\&Fitriasari, 2020).

Pelaksanaan kegiatan pelatihan dan pendampingan pembuatan Nata de Cashew dengan bahan dasar daging buah/buah semu jambu metedisajikan pada Gambar 1 berikut.

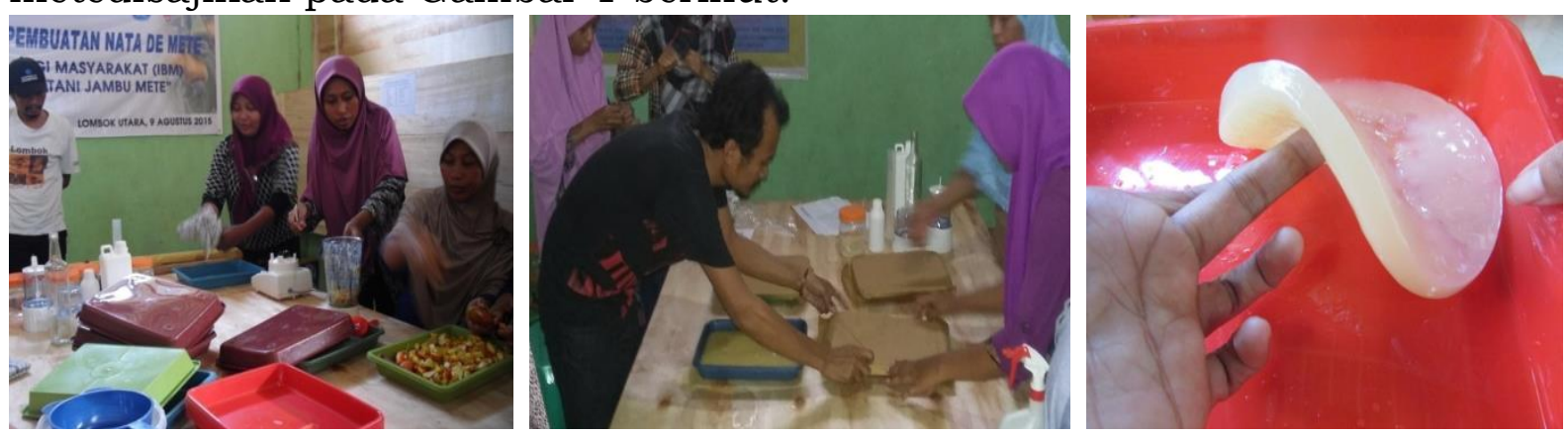

Gambar 1. Kegiatan pelatihanpembuatan Nata de Cashew

\section{Tahap Evaluasi}

Pada tahap ini, tim melakukan evaluasi secara klasikal terhadap kegiatan pelatihan dan pendampingan pembuatan Nata de Cashewdengan 
menggunakan lembar observasi. Berdasarkan data hasil observasidiperoleh data sebagai berikut:

Tabel 1. Hasil evaluasi kegiatan pemberdayaan masyarakat

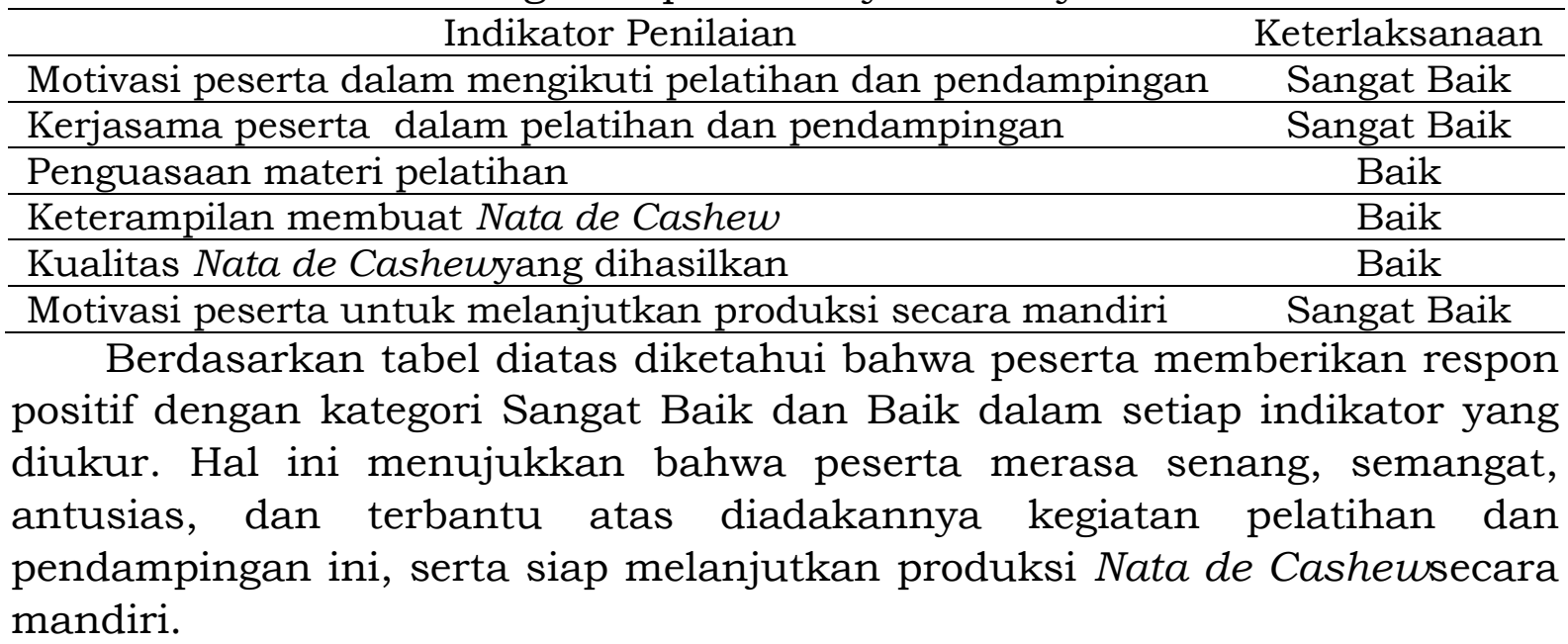

\section{KESIMPULAN}

Berdasarkan data hasil observasi dan evaluasi pelaksanaan kegiatan pelatihan dan pendampingan masyarakat dalam membuat Nata de Cashew, maka dapat disimpulkan bahwaimplementasi konsep bioentrepreneurship melalui pelatihan pembuatan Nata de Cashewefektif meningkatkan pengetahuan dan keterampilan peserta. Hal ini dibuktikan yaitu: (1) penguasan materi dan keterampilan peserta dalam membuat Nata de Cashewdikategorikan Baik; (2)kualitas Nata de Cashewyang dihasilkan dikategorikan Baik; (3) Motivasi, minat, dan kerjasama peserta selama pelaksanaan pelatihan dan pendampingan dikategorikan Sangat Baik; (4) Motivasi pesertauntuk produksi Nata de Cashew secara mandiri juga dikategorikan Baik.

\section{REKOMENDASI}

Kegiatan pemberdayaan masyarakatsejenis disarankan untuk dikerjakan di tempat lainnya yang memiliki potensi lokal jambu mete agar dapat meningkatkan pengetahuan, keterampilan, dan motivasi wirausaha masyarakat berbasis potensi lokal. Kegiatan ini direkomendasi sebagai solusi mengurangi limbah daging buah jambu mete dan menghindari perubahan $\mathrm{pH}$ tanah pada lahan perkebunan akibat penimbunan limbah tersebut.

\section{UCAPAN TERIMA KASIH}

Kegiatan pemberdayaan masyarakat dengan judul "Implementasi Konsep Bioentreprenurship berbasis Potensi Lokal melalui Pelatihan Pembuatan Nata de Cashew" dapat diselesaikan dengan baik atas bantuan banyak pihak lainnya. Khususnya kami sampaikan terima kasih kepada (1) Pimpinan Fakultas Sains, Teknik, dan Terapan (FSTT) Universitas Pendidikan Mandalika, (2) Masyarakat Dusun Menggala sebagai peserta pelatihan. 


\section{DAFTAR PUSTAKA}

Anwar, M.,Supardi \& Sugiharto. (2012). Pengembangan Perangkat Pembelajaran Biologi dengan Pendekatan Bioenterpreneurship untuk Meningkatkan Keterampilan Proses Ilmiah dan Minat Berwirausaha Siswa. Innovative Journal of Curriculum and Educational Technology, 1 (1), 38-44. https://doi.org/10.15294/ijcet.v1i1.129

Avisena, M.I.R. (2020). Pemerintah Luncurkan Program Ciptakan Wirausaha. [Online]. Tersedia: https://www.medcom.id/ekonomi/bisnis/JKRAXA5k -pemerintah-luncurkan-program-ciptakan-wirausaha

Langer, L.J. (2014). Building a curriculum for bioentrepreneurs. [Online]. Tersedia:http://www.nature.com/bioent/2014/140801/full/bioe.2014. 9.html

Muliadi, A. \& Arjun, M.A. (2018). IbM Pemberdayaan Petani Jambu Mete berbasis Entrepreneurship. Jurnal Ilmiah IKIP Mataram, 3 (1), 576577.https://jurnal.ikipmataram.ac.id/index.php/jiim/article/view/153

Muliadi, A. \& Arjun, M.A. (2016). IbM Pembinaan Petani Kopra Berbasis Entrepreneurship. Lumbung Inovasi: Jurnal Pengabdian Kepada $\begin{array}{llll}\text { Masyarakat, } & 1 & \text { (1), }\end{array}$ https://ojs.ikipmataram.ac.id/index.php/lumbunginovasi/article/view $\angle 10$

Muliadi, A. (2020). Microbiology Learning Based on Bioentrepreneurship: Prospective Teacher's Perception. Jurnal Ilmu Sosial dan Pendidikan, 4 (4), 352-357.http://dx.doi.org/10.36312/jisip.v4i4.1527

Muliadi, A. (2019). Pembelajaran Biologi Berbasis Entrpreneurship. Proceeding National Conference: Education, Social Science, and Humaniora, 1 (1), 269-275.

Muliadi, A., Mirawati, B. \& Azmi, I. (2020). Implementasi Konsep Bioentrepreneurship melalui Pelatihan Pembuatan Nata De Coco. Intan Cendekia (Jurnal Pengabdian Masyarakat), 1 (1), 35-41. https://doi.org/10.47165/intancendekia.v1i1.105

Natadiwijaya, I.F., Rahmat, A., Redjeki, S. \& Anggraeni, S. (2018). Sikap Wirausaha Mahasiswa Pada Perkuliahan Bioteknologi Bermuatan Bioentrepreneurship. MANGIFERA EDU: Jurnal Biologi and Pendidikan Biologi, 3 (1), 40-51. https://doi.org/10.31943/mangiferaedu.v3i1.11

Sujarwo. (2011). Pendidikan Orang Dewasa. Dedikasi: Journal of Community Engagement, 2(3), 79-88.http://jurnal.uinbanten.ac.id/index.php/ dedikasi/article/view/1713

Utami, U., Harianie, L., Kusmiyati, N. \&Fitriasari, P.D. (2020). Pelatihan Pembuatan Nata de Coco pada PKK diTasikmadu, Lowokwaru, Kota Malang. Jurnal Pengabdian pada Masyarakat, 5 (1). https://doi.org/10.30653/002.202051.268

Warsino (2004). Mudah dan Praktis Membuat Nata de Coco. Jakarta: Agiomedia Pustaka

Wijayanti, F., Kumalaningsih, S., \& Effendi, M. (2012). Pengaruh Penambahan Sukrosa dan Asam Asetat Glacial terhadap Kualitas Nata dari Whey Tahu dan Substrat AirKelapa. Industria, 1 (2), 8693.https://industria.ub.ac.id/index.php/industri/article/view/106 